\title{
Workplace Violence Against Nurses in Psychiatric Hospital Settings \\ Perspectives from Saudi Arabia
}

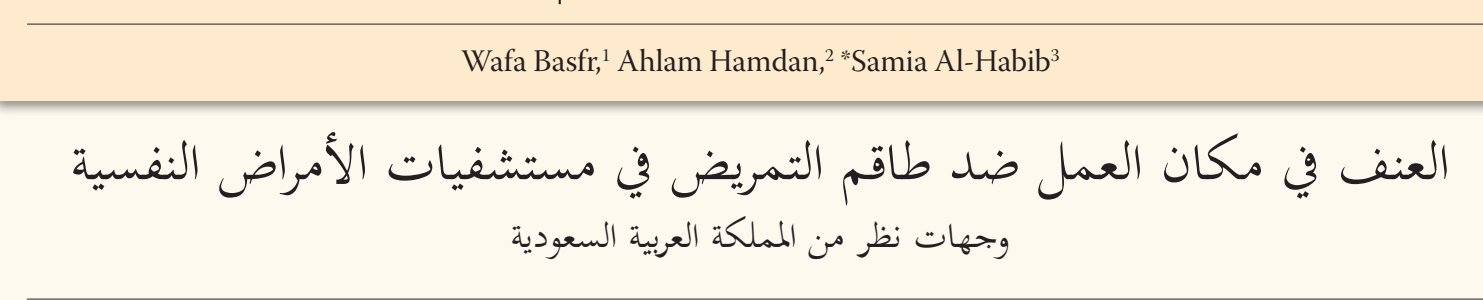

وفاء بـاصفر، أحلام حمدان، سامية الحبيب

ABSTRACT: Objectives: Workplace violence (WPV) has become a world-wide concern. This study aimed to measure the prevalence of WPV among nurses working in psychiatric hospitals in Saudi Arabia. Methods: This cross-sectional study was conducted at three psychiatric hospitals in Saudi Arabia between March and May 2017. Participants completed a self-reported questionnaire which was used to measure the prevalence and explore the associated factors of WPV. A multivariate logistic regression analysis was also performed. Results: A total of 310 nurses (response rate: 62\%) were included in this study. The prevalence of WPV against nurses was $90.3 \%$, of which $57.7 \%$ had been exposed to both physical and verbal abuse. More nurses were exposed to WPV during the morning shift than the evening shift (58.4\% versus $42.3 \%)$. Violent behaviour was exhibited mostly by the patients themselves $(81.3 \%)$. Over half of the nurses (57.4\%) required medical intervention in such cases. The majority of nurses felt either stressed (64.2\%) or anxious $(53.5 \%)$ and $34.2 \%$ felt depressed after the incident. Multivariate logistic regression analysis revealed that time of violence, source of violence, patient dissatisfaction with medical care and lack of organisational support for nurses were significantly associated with the occurrence of WPV in psychiatric units. Conclusion: WPV has reached an alarming rate among nurses in psychiatric hospitals in Saudi Arabia. It is crucial to invest in the prevention of WPV by constant training of workers and a mutual policy with the police and the civic prosecutor in Saudi Arabia on how to respond to violent psychiatric patients.

Keywords: Workplace Violence; Psychiatry; Nurse; Mental Health; Saudi Arabia.

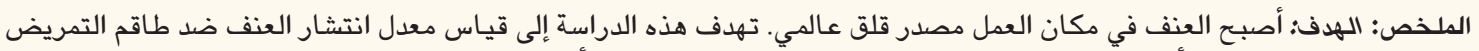

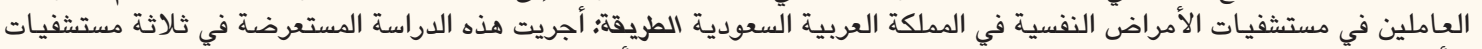

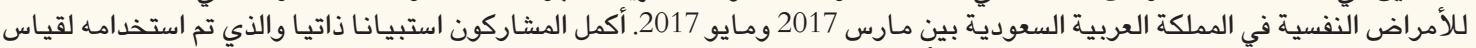

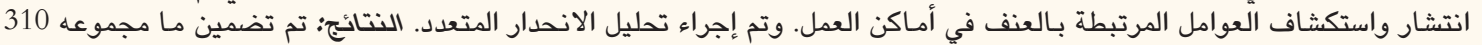

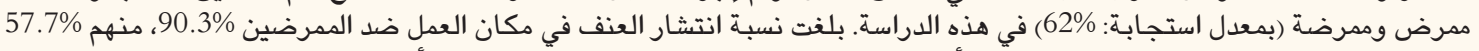

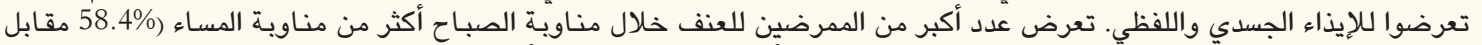

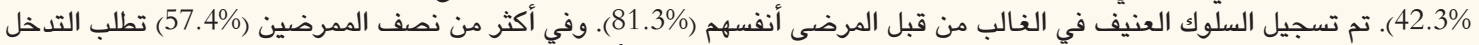

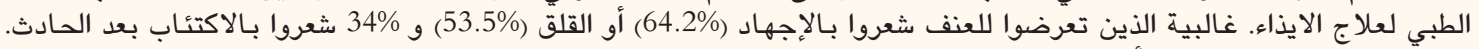

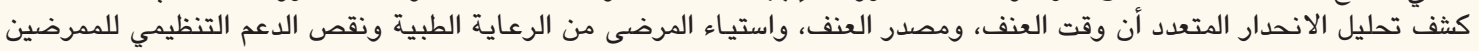

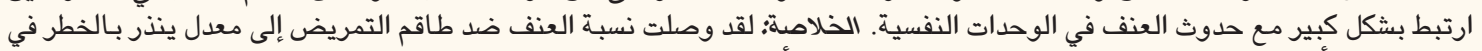

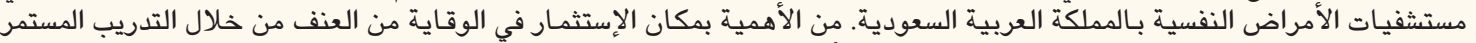

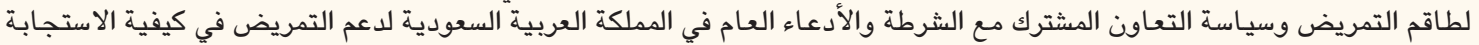

$$
\text { لعنف مرضى الطب النفسي. }
$$

\section{Advances in KNOWledge}

This study provided an insight into the estimate, associated factors and characteristics of workplace violence (WPV) amongst nurses working in three psychiatric hospitals in Saudi Arabia.

It highlighted the possible contextual factors surrounding workplace violence and the interactions with these factors.

\section{Application to Patient Care}

The present study emphasised the importance of patients' characteristics and their dissatisfaction of nurses and medical care, which might contribute to the occurrence of WPV.

The results of this study could help in tackling WPV with particular emphasis on the training of nurses on how to deal with and react to such violence safely and with special consideration to patients' mental health status. 
$\mathrm{W}$ ORKPLACE VIOLENCE (WPV) HAS BEEN A persistent problem that is accepted and generally overlooked by the public and professional organisations. ${ }^{1}$ There has been an increasing concern worldwide about the rise in WPV. It has been defined by The National Institute for Occupational Safety and Health "as violent acts (including physical assaults and threats of assaults) directed toward persons at work or on duty" and it "ranges from offensive or threatening language to homicide". 2 The World Health Organization highlighted that WPV includes "incidents where staff are abused, threatened or assaulted in circumstances related to their work, including commuting to and from work, involving an explicit or implicit challenge to their safety, well-being or health".

On an international level, it has been noticed that the highest number of these assaults are directed towards healthcare workers. ${ }^{4}$ A study in Canada found that the overall patient violence rate over a one year period was 1.52 incidents per 100,000 worked hours. ${ }^{5}$ Studies have emphasised that the well-being of healthcare staff and a healthy workplace are considered key components of effective healthcare systems. This should be applied to all sectors in any healthcare setting. This is particularly important among psychiatric nurses, who may be exposed to verbal, physical, emotional and psychological abuse. ${ }^{2,6}$ A systematic review by Iozzino et al. emphasised that almost one in five patients admitted to acute psychiatric units may commit an act of violence towards nurses working within these units. ${ }^{7}$ It is possible that these mentally unstable patients might be stressed and therefore express their anger towards the nurses who care for them. Iozzino et al. also found that factors associated with levels of violence in psychiatric units-including male gender, diagnosis of schizophrenia, substance use and a lifetime history of violence-were similar to factors associated with violence among individual patients. ${ }^{7}$

In Turkey, WPV is considered an important issue that adversely affects the personal lives of healthcare professionals and leads to a high staff turnover. ${ }^{8,9}$ These studies found that such violence is particularly common among nurses compared to other healthcare providers. Furthermore, among healthcare workers in Iran, it was found that nurses reported the highest rate of violence; $74.7 \%$ of the participants were subjected to psychological violence. ${ }^{10}$

In Saudi Arabia, WPV has been explored in primary healthcare and studies have revealed a wide range of WPV prevalence (28-67.5\% in 12 months), especially among nurses working in outpatient primary healthcare settings. ${ }^{11,12}$ However, this study proposes that WPV is more serious in other inpatient hospital settings, such as in psychiatric care units where patients are mentally unstable and might be more aggressive. The safety of hospital staff is of paramount importance for the continuity and quality of care in all healthcare settings. Therefore, this study aimed to measure the prevalence and explore the associated factors of WPV among nurses working in mental-care hospitals in Saudi Arabia.

\section{Methods}

This cross-sectional study was conducted between March and May 2017 at three main psychiatric hospitals located in the Western region of Saudi Arabia. A total of 938 nurses worked in these three hospitals and it was initially intended to include all nurses. However, it was only possible to distribute 500 questionnaires due to a high turn-over of nurses between hospitals, some nurses being on holiday, attending courses or being assigned to administrative work.

The questionnaires were distributed to all participants via their hospital postal system. Nurses working in direct contact with psychiatric patients were included. Participants were asked to complete a self-reported questionnaire, which has previously been used in several countries with a similar cultural context as Saudi Arabia. ${ }^{11,13-15}$ The language of the questionnaire was English in order to ensure its originality and avoid language-based distortions related to measurements of violence. The questionnaire was composed of 32 items under four sections: 1) sociodemographic variables; 2) questions measuring the frequency and type of WPV; 3) items asking participants on how they respond to such violence; and 4) open-ended questions exploring their needs in managing WPV The scale was scored with 'yes' or 'no' and participants were asked to tick the choices that applied to their situation. The explanation of the nature of each type of WPV (physical, verbal or both) was provided to all participants in a covering letter attached to the questionnaire, including examples of types of WPV.

The questionnaire was reviewed by two epidemiologists, four researchers and three professors in the Nursing College of Suliman AlFaqih in order to check its consistency, appropriateness and the relevance of the items. Furthermore, a pilot study including 30 nurses was conducted to ensure questionnaire applicability, wording and to identify any ambiguities in the items, after which the suggested changes were implemented and the questionnaire was modified accordingly. This pilot study is not reported here and was excluded from the results and analysis of the present study. Completed questionnaires were returned to a dedicated postal box in each hospital. All written materials were protected in secure closed cabinets accessible only to the researchers.

Data were analysed using Statistical Package for Social Sciences (SPSS), Version 22.0 (IBM Corp., Armonk, New York, USA). The level of statistical significance was set 
at $P \leq 0.05$. A multivariate logistic regression model using a forward (Wald) model was also performed.

A consent form was signed by all participants and confidentiality was ensured by maintaining a completely anonymous involvement in the study. Approval for this study was obtained from the Instructional Review Board Ethics Committee of Fakeeh College for Medical Sciences, Riyadh, Saudi Arabia.

\section{Results}

A total of 310 nurses (response rate: 62\%) completed the questionnaire and were included in the study. During the study period, many nurses were in transition between various departments, on leave or not interested in participating. The majority of the participants were middleaged married Saudi females, mainly working in the inpatient department, with a diploma degree in nursing and an experience of $1-10$ years [Table 1].

The prevalence of WPV against nurses was 90.3\%; 43.2\% were exposed to WPV more than three times in the last year and $57.7 \%$ had experienced both physical and verbal abuse. Most nurses were exposed to WPV during their morning shift (58.4\%) followed by the afternoon (50.3\%), evening (42.3\%) and night shift (33.9\%). The majority of violence originated from the patients themselves (81.3\%) and some WPV came from their relatives $(30 \%)$, visitors $(26.1 \%)$, or co-workers $(25.8 \%)$ [Table 2].

The majority of participants were rarely $(24.2 \%)$ or sometimes (32.3\%) concerned about WPV. After exposure to WPV, $57.4 \%$ of nurses required medical intervention and $15.8 \%$ experienced life-threatening acts that required emergency care. The majority felt either stress (64.2\%) or anxiety (53.5\%), while 34.2\% felt depressed and few $(8.4 \%)$ were not interested in attending work and were considering leaving their job [Table 2]. Nurses differed in their response to WPV and many selected more than one option when reacting to such acts. Over half of the nurses (54.2\%) would report the WPV to their manager, $40.6 \%$ spoke to colleagues and $30 \%$ requested to be transferred to another department [Table 3].

Participants perceived that psychological problems (69.7\%), shortage of staff (44.8\%), denial of patients' request for admission (41\%), smoking prohibition in thepsychiatric inpatient wards (37.1\%), overcrowding of the inpatient wards (33.9\%), long waiting times in the outpatient clinics $(29.7 \%)$ and violation of visiting hours (28.4\%) contributed to WPV [Table 4]. Participants also selected options from a range of preventive measures and the required resources to tackle WPV. The majority (61\%) chose to train nurses on managing WPV and how to cope with stress associated with such violence. Additionally, over half of the participants (56\%) selected the option that addressed the importance of policies
Table 1: Characteristics of nurses working at psychiatric hospitals in Saudi Arabia $(\mathrm{N}=310)$

\begin{tabular}{|c|c|}
\hline Characteristic & n (\%) \\
\hline \multicolumn{2}{|l|}{ Age } \\
\hline $20-29$ & 95 (30.6) \\
\hline 30-39 & $158(51)$ \\
\hline $40-49$ & $40(12.9)$ \\
\hline $50-59$ & $17(5.5)$ \\
\hline \multicolumn{2}{|l|}{ Gender } \\
\hline Male & $142(45.8)$ \\
\hline Female & $168(54.2)$ \\
\hline \multicolumn{2}{|l|}{ Marital status } \\
\hline Single & $95(30.6)$ \\
\hline Married & $193(62.3)$ \\
\hline Divorced & $14(4.5)$ \\
\hline Widow & $8(2.6)$ \\
\hline \multicolumn{2}{|l|}{ Nationality } \\
\hline Saudi Arabian & $214(69)$ \\
\hline Not Saudi Arabian & $96(31)$ \\
\hline \multicolumn{2}{|l|}{ Qualification in nursing } \\
\hline Diploma & $190(61.3)$ \\
\hline Bachelor & $103(33.2)$ \\
\hline Master & $17(5.5)$ \\
\hline \multicolumn{2}{|c|}{ Experience in psychiatric units in years } \\
\hline$<1$ & $31(10)$ \\
\hline $1-5$ & 85 (27.4) \\
\hline $6-10$ & $105(33.9)$ \\
\hline $11-15$ & $43(13.9)$ \\
\hline$>15$ & $46(14.8)$ \\
\hline \multicolumn{2}{|l|}{ Working shift } \\
\hline Day & $132(42.6)$ \\
\hline Evening & $35(11.3)$ \\
\hline Night & $19(6.1)$ \\
\hline Rotating days and nights & $46(14.8)$ \\
\hline Rotating days, evenings and nights & $78(25.2)$ \\
\hline \multicolumn{2}{|l|}{ Psychiatric department } \\
\hline Emergency & $54(17.4)$ \\
\hline Inpatient & $204(65.8)$ \\
\hline Outpatient & $52(16.8)$ \\
\hline
\end{tabular}

related to WPV. Many (45\%) also chose the option of awareness programmes to the public and staff with regards to unacceptable violent behaviour in a hospital environment. Some (39.4\%) selected the option of the role of organisational support for victims of violence.

Univariate analysis of WPV occurrence revealed significant associations with several factors. However, a multivariate logistic regression revealed the dependent 
Table 2: Prevalence, types and characteristics of workplace violence experienced by nurses working at psychiatric hospitals in Saudi Arabia $(\mathrm{N}=310)$

\begin{tabular}{|c|c|}
\hline WPV characteristic & n (\%) \\
\hline \multicolumn{2}{|l|}{ Experienced violence at work } \\
\hline Yes & $280(90.3)$ \\
\hline No & $30(9.7)$ \\
\hline \multicolumn{2}{|c|}{ Numbers of violent attacks in the previous year } \\
\hline Once & $59(19)$ \\
\hline Twice & $47(15.2)$ \\
\hline Three times & $43(13.9$ \\
\hline More than three times & $134(43.2)$ \\
\hline \multicolumn{2}{|l|}{ Type of violence } \\
\hline Physical abuse & $44(14.2)$ \\
\hline Verbal abuse & $61(19.7)$ \\
\hline Both & $179(57.7)$ \\
\hline \multicolumn{2}{|l|}{ Consequence of violence } \\
\hline Medical intervention required & $176(57.4)$ \\
\hline Life-threatening & $49(15.8)$ \\
\hline Both & $53(17.1)$ \\
\hline \multicolumn{2}{|c|}{ Concerned regarding violence at work } \\
\hline Never & $23(7.4)$ \\
\hline Rarely & $75(24.2)$ \\
\hline Sometimes & $100(32.3)$ \\
\hline Usually & $72(23.2)$ \\
\hline Always & $40(12.9)$ \\
\hline \multicolumn{2}{|l|}{ Timing of WPV } \\
\hline \multicolumn{2}{|l|}{ Morning } \\
\hline Yes & $181(58.4)$ \\
\hline No & $129(41.6)$ \\
\hline \multicolumn{2}{|l|}{ Afternoon } \\
\hline Yes & $156(50.3)$ \\
\hline No & $154(49.7)$ \\
\hline \multicolumn{2}{|l|}{ Evening } \\
\hline Yes & $131(42.3)$ \\
\hline No & $179(57.7)$ \\
\hline \multicolumn{2}{|l|}{ Night } \\
\hline Yes & 105 (33.9) \\
\hline No & $205(66.1)$ \\
\hline \multicolumn{2}{|l|}{ Source of violence } \\
\hline \multicolumn{2}{|l|}{ Patient's relative } \\
\hline Yes & $93(30)$ \\
\hline No & $217(70)$ \\
\hline \multicolumn{2}{|l|}{ Patient } \\
\hline Yes & $252(81.3)$ \\
\hline No & $58(18.7)$ \\
\hline
\end{tabular}

\begin{tabular}{lr} 
Co-worker & \\
Yes & $20(25.8)$ \\
No & $230(74.2)$ \\
Visitor & \\
Yes & $81(26.1)$ \\
No & $229(73.9)$ \\
Feeling after exposure to WPV & \\
Stress & \\
Yes & $199(64.2)$ \\
No & $111(35.8)$ \\
Anxiety & \\
Yes & $166(53.5)$ \\
No & $144(46.5)$ \\
Depression & \\
Yes & $106(34.2)$ \\
No & $204(65.8)$ \\
No interest in going to work; consider leaving job \\
Yes & $26(8.4)$ \\
No & $284(91.6)$ \\
WPV = workplace violence. & \\
\hline
\end{tabular}

Table 3: Participants' response to workplace violence at psychiatric hospitals in Saudi Arabia $(\mathrm{N}=310)$

$\begin{array}{lc}\text { Response after exposure to a WPV incident } & \text { n (\%)* } \\ \text { No response } & 89(28.7) \\ \text { Talking to family and friends } & 73(23.5) \\ \text { Request to be transferred to another department } & 93(30) \\ \text { Pretending nothing happened } & 50(16.1) \\ \text { Getting professional help } & 98(31.6) \\ \text { Getting help from the police } & 21(6.8) \\ \text { Warning the patient } & 79(25.5) \\ \text { Talking with colleagues } & 126(40.6) \\ \text { Reporting incident to the manager } & 168(54.2) \\ \text { Reacting with violence } & 46(14.8) \\ \text { Getting legal help } & 26(8.4) \\ \text { WPV = workplace violence. } & \\ \text { *Participants had the option of choosing more than one item. }\end{array}$

variables that were significantly associated with WPV after controlling for other socio-demographic variables and other possible confounders, such as age and years of experience. WPV mostly occurred during the evening time (odds ration [OR]: 2.91; 95\% confidence interval [CI]: 1.19-7.09; $P=0.02$ ). Patients (OR: 2.99; 95\% CI: $1.26-7.08 ; P=0.01$ ) and their relatives (OR: 0.29; 95\% CI: $0.11-0.74 ; P=0.01$ ) were the main sources of violence. Patients' dissatisfaction with nursing or medical care was significantly associated with more WPV 
Table 4: Participants' perception of causes of workplace violence at psychiatric hospitals in Saudi Arabia $(\mathrm{N}=310)$

$\begin{array}{lc}\text { Perceived causes of WPV } & \text { n (\%)* } \\ \text { Violation of visiting hours } & 88(28.4) \\ \text { Long waiting periods in outpatient clinics } & 92(29.7) \\ \text { Psychological problems } & 216(69.7) \\ \text { Smoking prohibition in inpatient wards } & 115(37.1) \\ \text { Denial of patients' admission to the hospital } & 127(41) \\ \text { Delays in nursing care provision } & 54(17.4) \\ \text { Delays in medical care provision } & 65(21) \\ \text { Patient dissatisfaction with nursing or medical care } & 64(20.6) \\ \text { Shortage of staff } & 139(44.8) \\ \text { The patients' requests not satisfied } & 84(27.1) \\ \text { Poor organisation } & 68(21.9) \\ \text { Overcrowded inpatient ward } & 105(33.9) \\ \text { Patients' health condition } & 138(44.5) \\ \text { WPV = workplace violence. } & \\ \text { "Participants had the option of choosing more than one item. }\end{array}$

(OR: 2.70; 95\% CI: 1.03-7.09; $P=0.04$ ). The lack of organisational support to nurses exposed to such violence was significantly associated with the occurrence of WPV (OR: 0.33; 95\% CI: 0.14-0.79; $P=0.01$ ) [Table 5].

\section{Discussion}

The results of the present study showed that nurses in Saudi Arabia were exposed to WPV, similar to other nurses who work in psychiatric hospitals worldwide. However, there are some differences in terms of frequency and type of WPV as well as other associated factors. In the present study, the prevalence of WPV (90.3\%) was higher than that reported in studies from China (50-76\%), Egypt (27.7\%) and Taiwan (49.6\%). ${ }^{16-19}$ The high prevalence in the present study may be due to the lack of policies related to WPV in Saudi Arabian hospitals, which could contribute to the continuity of such violence.

It was previously reported in a study by HatchMaillette et al. that $100 \%$ of the nurses experienced WPV at some point in their careers. ${ }^{20}$ Such variability may be due to the different instruments used to measure WPV in various countries with diverse laws and health system regulations. Moreover, this might be because of differences in the definitions of violence and variations in the levels of under-reporting of WPV episodes by mental healthcare personnel. The high prevalence of WPV in the current study could also be explained by the nurses' lack of awareness of WPV, which reflects the lack of training and support from their hospital; this may subsequently lead to the occurrence of WPV.
Table 5: Multivariate logistic regression model using forward (Wald) model of factors associated with workplace violence towards nurses in psychiatric hospitals in Saudi Arabia

$\begin{array}{lcc}\text { Variable } & \begin{array}{c}\text { OR } \\ (\mathbf{9 5 \%} \mathbf{C I})\end{array} & \boldsymbol{P} \text { value } \\ \begin{array}{l}\text { Time violent incident occurred } \\ \text { Evening }\end{array} & \begin{array}{l}2.91 \\ (1.19-7.09)\end{array} & 0.02 \\ \text { Source of violence } & & \\ \text { Relatives } & 0.29 & 0.01 \\ & (0.11-0.74) & \\ \text { Patients } & 2.99 & 0.01 \\ & (1.26-7.08) & \\ \text { Cause } & & \\ \begin{array}{l}\text { Patient dissatisfaction with } \\ \text { nursing or medical care }\end{array} & 2.70 & 0.04 \\ \begin{array}{l}\text { Organisational support for } \\ \text { victims of violence }\end{array} & (1.03-7.09) & \\ \text { Constant } & 0.33 & 0.01 \\ \text { OR = odds ratio; CI = confidence interval. } & & \\ \end{array}$

These concerns should be explored further using in-depth interviews and/or focus groups in order to elaborate the dimensions and factors underlying their perceptions about WPV.

The current study's participants were exposed to both physical and verbal abuse, mostly during morning and afternoon shifts. This is consistent with other studies that showed a high level of both verbal abuse and physical violence towards healthcare professionals, in particular, mental healthcare workers. ${ }^{10,21,22}$ The current study showed that the source of WPV was mainly the psychiatric patients themselves followed by their relatives. This is similar to other studies which revealed that the main perpetrators of WPV were patients followed by their relatives..$^{23,24}$

In addition to possible physical consequences, psychological consequences may also be significant. ${ }^{1}$ Tonso et al. reported that almost one in three victims of violence (33\%) rated themselves as being in psychological distress, while in the current study almost two in three felt the same (64.2\%). ${ }^{25}$ A study by van Leeuwen et al. in the Dutch mental health system revealed that one in five healthcare professionals working in psychiatric inpatient units experienced mental health complications as a consequence of WPV. ${ }^{26}$ In addition, some (8.4\%) of the current study's participants expressed a lack of interest to go to work or considered leaving their job. This is consistent with Nijman et al's study that indicated that WPV was associated with a decrease in productivity and higher rates of work non-attendance. ${ }^{27}$ Violence against nurses is thought to contribute to low morale, high rates of sick leave and increased turnover. ${ }^{28}$ This may instigate a cycle, as decreased staffing levels and 
the presence of temporary staff can lead to more episodes of violence. ${ }^{29}$

The majority of the current participants responded to the WPV by reporting the incident to their manager (54.2\%), which is comparable with Speroni et al's study where nurses reported incidents to managers or supervisors. ${ }^{30}$ While several nurses $(40.6 \%)$ chose to talk to their colleagues about their exposure to such violence, $30 \%$ requested to be transferred to another department.

Participants' perceptions of the causes of WPV revealed multiple reasons, including psychological problems of patients, shortage of staff, denial of patients' request for admission, smoking prohibition in the psychiatric inpatient wards, overcrowded inpatient wards, long waiting times in outpatient clinics and during visiting hours. Park et al's study showed that heavy work mandates under time pressure caused by shortage of staff, less trust and justice and a high patient turn-over created stressful situations for patients, families and healthcare workers. ${ }^{23}$

There were some limitations in the current study. There was a relatively low response rate (62\%), but this could be due to several factors such as during the recruitment period, there was a high turn-over of nurses between hospitals and some were also on leave, attending courses or assigned to administrative work. However, it should be noted that other studies have reported an even lower response rate (25-26\%). ${ }^{15,25}$ There were discrepancies between the simple prevalence statistics and the regression statistics. This could be due to missing data in some of the items in the questionnaire. Additionally, some of the questionnaire sections allowed participants to choose more than one option and, hence, some estimates reflect these selections. Moreover, some healthcare workers who experienced serious physical or mental injuries due to WPV have left their jobs in mental healthcare and could not be reached. In addition, there might be a selection bias, resulting in more nurses who experienced WPV disproportionately completing the survey. The current findings should be seen in light of these limitations.

In future research, comparable methodologies, instruments and definitions could be used to establish a clearer conceptual framework. The authors' also suggest that in order to decrease the frequency of WPV, it is crucial to invest in its prevention by constant training of healthcare professionals to improve their verbal communication skills and other necessary techniques that are implemented in psychiatric units. However, even if staff are well-trained, WPV may still occur. Hence, it is of utmost importance that workers communicate that violence against them will not be tolerated under any circumstance and it may also have legal consequences.
For that purpose, it is fundamental for all mental health organisations to have a mutual policy, which may involve the police and the judicial system, on how to react to violent psychiatric patients.

\section{Conclusion}

In healthcare settings, WPV is an occupational hazard with detrimental effects on work-related health. Such violence has reached an alarming rate among nurses working in three psychiatric hospitals in Saudi Arabia. Workplace characteristics and the interface between patients and healthcare professionals are important contextual factors that can contribute to the development of WPV. This study revealed that important factors associated significantly with WPV included lack of organisational support for nurses as WPV victims, staffing levels and patients' and/or relatives' dissatisfaction with the psychiatric care. These factors must be kept in mind to create policies and manage violence in a psychiatric healthcare setting.

\section{CONFLICT OF INTEREST}

The authors declare no conflicts of interest.

\section{FUNDING}

No funding was received for this study.

\section{References}

1. Phillips JP. Workplace violence against health care workers in the United States. N Engl J Med 2016; 374:1661-9. https://doi.org/10. 1056/NEJMra1501998.

2. Centers for Disease Control and Prevention. Violence occupational hazards in hospitals. From: https://www.cdc.gov/niosh/docs/20 02-101/default.html Accessed: Dec 2018.

3. World Health Organization. Workplace violence: World Health Organisation 2005 From: https://www.who.int/violence injury prevention/injury/work9/en/index2.html Accessed: Dec 2018.

4. FederalBureau ofInvestigation,U.S.DepartmentofJustice. Workplace violence: Issues in response. From: https://www.fbi.gov/sta ts-services/publications/workplace-violence Accessed: Dec 2018.

5. Kling RN, Yassi A, Smailes E, Lovato CY, Koehoorn M. Characterizing violence in health care in British Columbia. J Adv Nurs 2009; 65:1655-63. https://doi.org/10.1111/j.1365-2648.20 09.05020.x.

6. Chapman R, Styles I, Perry L, Combs S. Nurses' experience of adjusting to workplace violence: A theory of adaptation. Int J Ment Health Nurs 2010; 19:186-94. https://doi.org/10.1111/j.14 47-0349.2009.00663.x

7. Iozzino L, Ferrari C, Large M, Nielssen O, de Girolamo G. Prevalence and risk factors of violence by psychiatric acute inpatients: A systematic review and meta-analysis. PloS One 2015; 10:e0128536. https://doi.org/10.1371/journal.pone.0128536.

8. Aytac S, Bozkurt V, Bayram N, Yildiz S, Aytac M, Akinci FS, et al. Workplace violence: A study of Turkish workers. Int J Occup Saf Ergon 2011; 17:385-402. https://doi.org/10.1080/10803548.20 11.11076902 
9. St-Pierre I, Holmes D. The relationship between organizational justice and workplace aggression. J Adv Nurs 2010; 66:1169-82. https://doi.org/10.1111/j.1365-2648.2010.05281.x.

10. Fallahi Khoshknab M, Oskouie F, Najafi F, Ghazanfari N, Tamizi Z, Ahmadvand $\mathrm{H}$. Psychological violence in the health care settings in Iran: A cross-sectional study. Nurs Midwifery Stud 2015; 4:e24320. https://doi.org/10.17795/nmsjournal24320.

11. Algwaiz WM, Alghanim SA. Violence exposure among health care professionals in Saudi public hospitals. A preliminary investigation. Saudi Med J 2012; 33:76-82.

12. El-Gilany AH, El-Wehady A, Amr M. Violence against primary health care workers in Al-Hassa, Saudi Arabia. J Interpers Violence 2010; 25:716-34. https://doi.org/10.1177/0886260509 334395 .

13. Tiruneh BT, Bifftu BB, Tumebo AA, Kelkay MM, Anlay DZ, Dachew BA. Prevalence of workplace violence in Northwest Ethiopia: A multivariate analysis. BMC Nurs 2016; 15:42. https://doi.org/10.1186/s12912-016-0162-6.

14. Fallahi Khoshknab M, Oskouie F, Ghazanfari N, Najafi F, Tamizi Z, Afshani $\mathrm{S}$, et al. The frequency, contributing and preventive factors of harassment towards health professionals in Iran. Int J Community Based Nurs Midwifery 2015; 3:156-64.

15. di Martino V. Workplace violence in the health sector. From https://www.who.int/violence_injury_prevention/injury/en/ WVsynthesisreport.pdf Accessed: Dec 2018.

16. Kwok RP, Law YK, Li KE, Ng YC, Cheung MH, Fung VK, et al. Prevalence of workplace violence against nurses in Hong Kong. Hong Kong Med J 2006; 12:6-9.

17. Wu S, Zhu W, Li H, Lin S, Chai W, Wang X. Workplace violence and influencing factors among medical professionals in China. Am J Ind Med 2012; 55:1000-8. https://doi.org/10.1002/ajim. 22097.

18. Abbas MA, Fiala LA, Abdel Rahman AG, Fahim AE. Epidemiology of workplace violence against nursing staff in Ismailia Governorate, Egypt. J Egypt Public Health Assoc 2010; 85:29-43.

19. Wei CY, Chiou ST, Chien LY, Huang N. Workplace violence against nurses--Prevalence and association with hospital organizational characteristics and health-promotion efforts: Crosssectional study. Int J Nurs Stud 2016; 56:63-70. https://doi.org/10. 1016/j.ijnurstu.2015.12.012.

20. Hatch-Maillette MA, Scalora MJ, Bader SM, Bornstein BH. A gender-based incidence study of workplace violence in psychiatric and forensic settings. Violence Vict 2007; 22:449-62. https://doi.org/10.1891/088667007781553982.
21. Swain N, Gale C, Greenwood R. Patient aggression experienced by staff in a New Zealand public hospital setting. N Z Med J 2014; 127:10-18.

22. McKinnon B, Cross W. Occupational violence and assault in mental health nursing: A scoping project for a Victorian Mental Health Service. Int J Ment Health Nurs 2008; 17:9-17. https://doi.org/10. 1111/j.1447-0349.2007.00499.x.

23. Park M, Cho SH, Hong HJ. Prevalence and perpetrators of workplace violence by nursing unit and the relationship between violence and the perceived work environment. J Nurs Scholarsh 2015; 47:87-95. https://doi.org/10.1111/jnu.12112.

24. Spector PE, Zhou ZE, Che XX. Nurse exposure to physical and nonphysical violence, bullying, and sexual harassment: A quantitative review. Int J Nurs Stud 2014; 51:72-84. https://doi.org/10.1016/j. ijnurstu.2013.01.010.

25. Tonso MA, Prematunga RK, Norris SJ, Williams L, Sands N, Elsom SJ. Workplace violence in mental health: A Victorian Mental Health workforce survey. Int J Ment Health Nurs 2016; 25:444-51. https://doi.org/10.1111/inm.12232.

26. van Leeuwen ME, Harte JM. Violence against mental health care professionals: Prevalence, nature and consequences. J Forens Psychiatry Psychol 2017; 28:581-98. https://doi.org/10.1080/14 789949.2015.1012533.

27. Nijman H, Bowers L, Oud N, Jansen G. Psychiatric nurses' experiences with inpatient aggression. Aggress Behav 2005; 31:217-27. https://doi.org/10.1002/ab.20038.

28. Needham I, Abderhalden C, Halfens RJ, Dassen T, Haug HJ, Fischer JE. The effect of a training course in aggression management on mental health nurses' perceptions of aggression: A cluster randomised controlled trial. Int J Nurs Stud 2005; 42:649-55. https://doi.org/10.1016/j.ijnurstu.2004.10.003.

29. Bowers L, Simpson A, Alexander J, Hackney D, Nijman H, Grange A, et al. The nature and purpose of acute psychiatric wards: The Tompkins Acute Ward Study. J Ment Health 2005; 14:625-35. https://doi.org/10.1080/09638230500389105.

30. Speroni KG, Fitch T, Dawson E, Dugan L, Atherton M. Incidence and cost of nurse workplace violence perpetrated by hospital patients or patient visitors. J Emerg Nurs 2014; 40:218-28. https://doi.org/10.1016/j.jen.2013.05.014. 